\title{
Fault Tree Establishment of Flight Conflict Based on the HAZOP Method
}

\author{
Qike WU ${ }^{1,2, a}$, Xusheng GAN ${ }^{1,2, b}$, Dengkai YAO ${ }^{1,2, c}$, Qianrui SUN ${ }^{1,2, c}$ \\ ${ }^{1}$ Air Traffic Control and Navigation College, Air Force Engineering University, Xi'an, Shaanxi, \\ 710051, China \\ ${ }^{2}$ National Key Laboratory of Air Traffic Collision Prevention, Xi'an, Shaanxi, 710051, China \\ a wuqiklove@163.com, b ganxusheng123@163.com, ${ }^{\mathrm{c}}$ 308541465@qq.com
}

Keywords: Safety Engineering; HAZOP; Fault Tree Analysis; Air Traffic Management; Reliability Analysis

\begin{abstract}
Aiming at the issues of subjectivity, coverage and ambiguity, this paper presents a systematic approach to constructing fault trees of flight conflict at airport based on HAZOP. First, the necessary deviation events are determined by associating the HAZOP guide words with the ATC parameters of terminal area, the causes and results of the deviation are analyzed in order to determine the paternity of the effectiveness of the proposed approach, and then the modeling process of the airport where two planes flight conflict happened in the United States is presented. This method can establish fault tree normatively, and provide a scientific and rational way to identify the inherent or potential risks within the airport.
\end{abstract}

\section{Introduction}

Hazard and Operability (HAZOP) analysis can help the technical designer find dangerous factors earlier and improve technical process safety, and it can also identify the potential hazards and operating problems, clarify the formation and propagation of potential accidents, assess the consequences of accidents, and propose measures to reduce the risk of the proposal[1]. Among the existing safety management technologies and system analysis methods, HAZOP method is a important one with the characteristics of its "innovative thinking by guide words" ",collective wisdom" and "scientific and systematic analysis to the accident scenario" . It has acquired a wide range of applications in current international chemical process safety management technologies and methods.

With the rapid development of the aviation industry, the application of HAZOP analysis method has been further extended to the aerospace sector in recent years, and to ATM by NATS (National Air Traffic Services). By 2013, the number of HAZOP analysis projects has reached tens of millions all over the world, and it has been widely used in risk assessment in European and American countries. Nevertheless, the application of HAZOP method started late in air traffic control in our country[2].So this paper will combine HAZOP with fault tree method and analyze the flight conflict scenario between approach aircrafts and departure aircrafts over the airport. Not only can we succeed in introducing HAZOP method into the ATC, but also solve the problems like redundancy in the establishment of FTs, which can be reliable basis for decision-makers.

\section{The Presentation of HAZOP and Fault Tree Analysis Methods}

As shown in Figure 1, HAZOP analysis method based on fault tree is established over the airport. General procedure of HAZOP analysis is in the left part of Figure 1. 


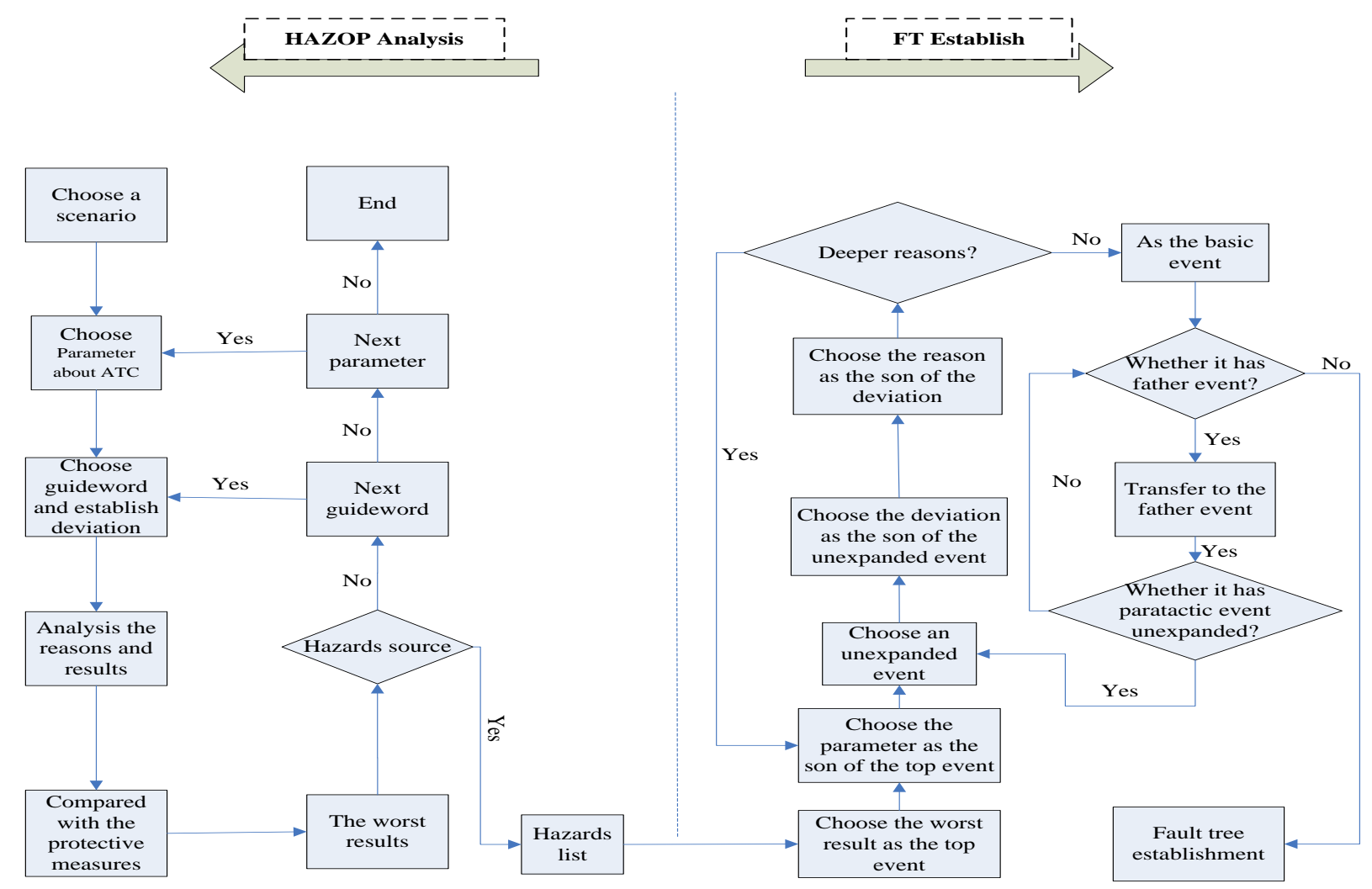

Fig.1 Flow chart of building fault tree with HAZOP analysis

Step 1: Determine the scenario.

Make sure that the purpose, object and scope of the scenario are as clearly as possible.

Step 2: Select ATC parameters.

A flight program will be divided into many process nodes. One parameter is element or characteristic in the design of each node. Parameters must be selected to describe the characteristics of the scenario.

Step 3: Select guidewords and establish deviations.

Deviation is the combination of guidewords and parameters, and can be generally expressed as follows:" guidewords + parameter = deviation", which means combining ATC parameters with guidewords to build the structure and determine the significant deviation. For example, " None + flow $=$ no flow", representing that there is no plane flew overhead in the scenario. Using the guidewords to describe the problems can ensure the unity of HAZOP method and the systematization of the analysis.

Step 4: Generate hazards list and establish FTs.

Do HAZOP analysis according to the flow chart in the left part of Figure 1. After traversing all the guidewords and parameters, choose a meaningful deviation, and then generate hazards list. Establish FTs taking the worst result as the top event.

Step 5:Find out the basic events that influence the top event most, and adopt the relevant preventive measures.

HAZOP is qualitative analysis, while the quantitative calculations can be made by FTA to determine the probability of accident. We acquire the deviation and hazards list with HAZOP method, and then make in-depth accident analysis with FTA, which can be a complete process of accident scenario analysis.

\section{Practical example}

Taking the flight conflict in Anchorage, America as an example. Shortly after local time 12:00 at midnight in May 21,2010, a Boeing 747 plane belonging to Cargolux Airlines International flew from Anchorage to $\mathrm{O}^{\prime}$ Hare International Airport in Chicago and two crew members were on board. 
Meanwhile, a A319 plane belonging to American Airlines were ready for landing, flew from Phonenix to Anchorage in Alaska and 138 passengers were on board. The A319 plane had to pull up and go around at a low altitude because of wind shear. In the course of the operation, the vertical interval between two aircrafts was only 100 feet and the horizontal interval was only 0.3 nautical miles[3].

We know that this is a case of flight confict occurred during the approach and departure. Our purpose is to identify the causes and the key factors of the accident so that we can formulat appropriate measures to avoid the occurrence of similar case. After determining the scenario, we would choose ATC parameters from four aspects(including human, machine, environment and management), which are instruction, handover, transmission and descend. According to the views of experts like controllers, flight commanders, navigators, weatherman, we make a practical significant deviation by combining guidewords with ATC parameters, and traverse all the deviations related to flight conflict. Finally, a hazards list of the risk scanarios is obtained as shown in Table 1[4][5].

Table 1 The hazards list(Portion)

\begin{tabular}{|c|c|c|c|c|c|}
\hline Number & Parameter & Guidewords & Deviation & Reason & The worst result \\
\hline H1 & Handover & None & $\begin{array}{l}\text { Forget to } \\
\text { handover }\end{array}$ & $\begin{array}{l}1 \text { The pilot did not ask } \\
\text { forwardly } \\
2 \text { Human error from } \\
\text { controller } \\
3 \text { Communication } \\
\text { equipment faults }\end{array}$ & $\begin{array}{l}\text { Flight conflict、 } \\
\text { Collision accident }\end{array}$ \\
\hline $\mathrm{H} 2$ & & Early & Handover earlier & $\begin{array}{l}\text { There were too many } \\
\text { flights in approach area. }\end{array}$ & Flight conflict \\
\hline H3 & & Late & Handover later & $\begin{array}{l}\text { Controllers ignored it } \\
\text { because of overload }\end{array}$ & Flight conflict \\
\hline $\mathrm{T} 1$ & Transmission & None & No transmmion & $\begin{array}{l}1 \text { The pilot chose the error } \\
\text { frequency channel. } \\
2 \text { Communication failure } \\
\text { crossing navigation station. }\end{array}$ & Flight conflict \\
\hline $\mathrm{T} 2$ & & As Well As & $\begin{array}{l}\text { Interference } \\
\text { and noise }\end{array}$ & $\begin{array}{l}1 \text { The effects from another } \\
\text { electronic equipments. } \\
2 \text { Turn on/off communication } \\
\text { button }\end{array}$ & Flight conflict \\
\hline Т3 & & Other Than & $\begin{array}{l}\text { False-alarm } \\
\text { from TCAS }\end{array}$ & Height indicator is broken & $\begin{array}{l}\text { Flight conflict、Diver } \\
\text { attention from flying }\end{array}$ \\
\hline
\end{tabular}

\section{Establishment of Fault Tree}

The determination of the top event plays a key role on the FTA. We would take the worst result just like flight conflict as the top event based on the hazards list as Table 1, then establish the FT according to the logic process of the interpretation[6][7]. Deviation is chosen as the intermediate event, the results as new top event and causes as new basic event, and we can acquire the fault tree in Figure 2 following the steps in the right part of Figure 1. 


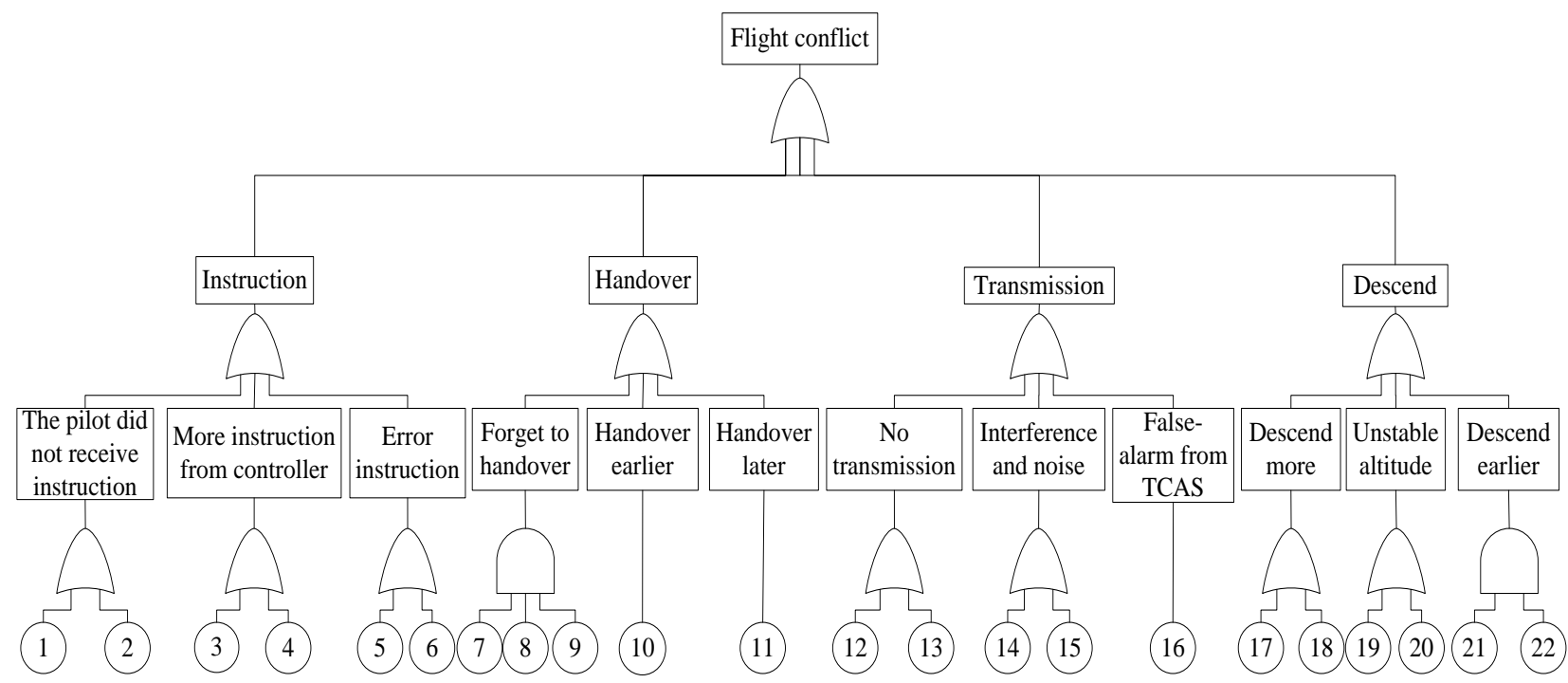

Fig. 2 Fault tree of flight conflict

The basic events of the flight conflict are shown in Table 2[8].

Table 2 Fundamental events of fault tree

\begin{tabular}{|c|c|c|c|}
\hline Numbe & Basic events & Number & Basic events \\
\hline 1 & Wireless channel is busy & 12 & $\begin{array}{l}\text { The pilot chose the error frequency } \\
\text { channel }\end{array}$ \\
\hline 2 & The controller is busy doing anything else & e 13 & $\begin{array}{l}\text { Communication failure crossing } \\
\text { navigation station }\end{array}$ \\
\hline 3 & $\begin{array}{l}\text { Expression is not clear as the } \\
\text { controller' s scarce capacity }\end{array}$ & 14 & $\begin{array}{l}\text { The effects from another electronic } \\
\text { equipments }\end{array}$ \\
\hline 4 & The flight is in emergency & 15 & Turn on/off communication button \\
\hline 5 & The flights has the similar callsign & 16 & Height indicator is broken \\
\hline 6 & The tower controller can' t divide & 17 & Measuring error \\
\hline 7 & $\begin{array}{l}\text { his attention reasonably as workload } \\
\text { The pilot doesn' t ask forwardly }\end{array}$ & 18 & $\begin{array}{l}\text { Responder model C displays error } \\
\text { altitude }\end{array}$ \\
\hline 8 & The human error from controller & 19 & $\begin{array}{l}\text { Upper wind、Turbulence、wind } \\
\text { shear }\end{array}$ \\
\hline 9 & Communication equipment faults & 20 & Wake flows \\
\hline 10 & $\begin{array}{l}\text { The pilot switch the transmission } \\
\text { channel earlier }\end{array}$ & 21 & Operation error from pilots \\
\hline 11 & $\begin{array}{l}\text { The approach controller } \\
\text { ignores it as workload }\end{array}$ & 22 & Instruction error from controllers \\
\hline
\end{tabular}

\section{Fault tree Quantitative Analysis}

The structure importance should be analyzed in order to determine the influence of the basic events to the top event. The calculation of that of the basic events is in type (1) [6].

$$
I_{\Psi}(i)=\frac{1}{K} \sum_{j=1}^{m} \frac{1}{R_{j}}
$$

The $K$ in type(1) is the number of the minimum cut sets in the fault tree, the $m$ is the number of the minimum cut sets that contain the ith basic event. The $R_{j}$ is the number of the $j$ th minimum cut sets that contain the ith basic event.

We can get the structure importance of basic events in Table 3. The result shows that the single-events are the most important influence factors. Because their number is big, we would do more precise quantitative analysis as followed. 
Table3 Structure importance of basic events

\begin{tabular}{cccc}
\hline $\begin{array}{c}\text { Basi } \\
\text { c } \\
\text { event }\end{array}$ & $\begin{array}{c}\text { Structure } \\
\text { importance }\end{array}$ & $\begin{array}{c}\text { Basi } \\
\mathrm{c} \\
\text { event }\end{array}$ & $\begin{array}{c}\text { Structure } \\
\text { importance }\end{array}$ \\
\hline $\mathrm{X}_{1}$ & 0.0526 & $\mathrm{X}_{12}$ & 0.0526 \\
$\mathrm{X}_{2}$ & 0.0526 & $\mathrm{X}_{13}$ & 0.0526 \\
$\mathrm{X}_{3}$ & 0.0526 & $\mathrm{X}_{14}$ & 0.0526 \\
$\mathrm{X}_{4}$ & 0.0526 & $\mathrm{X}_{15}$ & 0.0526 \\
$\mathrm{X}_{5}$ & 0.0526 & $\mathrm{X}_{16}$ & 0.0526 \\
$\mathrm{X}_{6}$ & 0.0526 & $\mathrm{X}_{17}$ & 0.0526 \\
$\mathrm{X}_{7}$ & 0.0175 & $\mathrm{X}_{18}$ & 0.0526 \\
$\mathrm{X}_{8}$ & 0.0175 & $\mathrm{X}_{19}$ & 0.0526 \\
$\mathrm{X}_{9}$ & 0.0175 & $\mathrm{X}_{20}$ & 0.0526 \\
$\mathrm{X}_{10}$ & 0.0526 & $\mathrm{X}_{21}$ & 0.0263 \\
$\mathrm{X}_{11}$ & 0.0526 & $\mathrm{X}_{22}$ & 0.0263 \\
\hline
\end{tabular}

According to the FT, we can get the $Q$ which is probability of the top event.

$$
Q=1-\prod_{i=1}^{19}\left(1-P_{E i}\right)
$$

Table4 Occurrence probability of basic events

\begin{tabular}{cccc}
\hline $\begin{array}{c}\text { Basi } \\
\mathrm{c} \\
\text { event }\end{array}$ & $\begin{array}{c}\text { Probabilit } \\
\mathrm{y} / \mathrm{d}^{-1}\end{array}$ & $\begin{array}{c}\text { Basi } \\
\mathrm{c} \\
\text { event }\end{array}$ & $\begin{array}{c}\text { Probabilit } \\
\mathrm{y} / \mathrm{d}^{-1}\end{array}$ \\
\hline $\mathrm{X}_{1}$ & 0.02200 & $\mathrm{X}_{12}$ & 0.02700 \\
$\mathrm{X}_{2}$ & 0.00300 & $\mathrm{X}_{13}$ & 0.00900 \\
$\mathrm{X}_{3}$ & 0.05500 & $\mathrm{X}_{14}$ & 0.00200 \\
$\mathrm{X}_{4}$ & 0.00400 & $\mathrm{X}_{15}$ & 0.00500 \\
$\mathrm{X}_{5}$ & 0.00300 & $\mathrm{X}_{16}$ & 0.01200 \\
$\mathrm{X}_{6}$ & 0.05800 & $\mathrm{X}_{17}$ & 0.00300 \\
$\mathrm{X}_{7}$ & 0.03200 & $\mathrm{X}_{18}$ & 0.01400 \\
$\mathrm{X}_{8}$ & 0.06100 & $\mathrm{X}_{19}$ & 0.02500 \\
$\mathrm{X}_{9}$ & 0.00400 & $\mathrm{X}_{20}$ & 0.01400 \\
$\mathrm{X}_{10}$ & 0.02500 & $\mathrm{X}_{21}$ & 0.04700 \\
$\mathrm{X}_{11}$ & 0.04500 & $\mathrm{X}_{22}$ & 0.00400 \\
\hline
\end{tabular}
the

$P_{E i}$ stand for the probability of the ith minimum cut sets.

We can determine the probability of the basic events as Table 4 by studying the survey analysis of flight conflicts from 1994 to2014 in reference[3], and then get $I_{P(i)}$ which is the probability importance coefficient of the basic event as shown in Table 5 by solving simultaneous type(2)and type(3).

$$
I_{P(\mathrm{i})}=\frac{\partial Q}{\partial q_{i}}
$$

Table 5 Probability importance of occurrence of basic events

\begin{tabular}{clcl}
\hline $\begin{array}{c}\text { Basic } \\
\text { event }\end{array}$ & \multicolumn{1}{c}{$\begin{array}{c}\text { Coefficient of } \\
\text { probability }\end{array}$} & $\begin{array}{c}\text { Basic } \\
\text { event }\end{array}$ & $\begin{array}{c}\text { Coefficient of } \\
\text { probability }\end{array}$ \\
\hline $\mathrm{X}_{1}$ & $7.375379 * 10^{-9}$ & $\mathrm{X}_{12}$ & $6.197708^{*} 10^{-9}$ \\
$\mathrm{X}_{2}$ & 0.99642535 & $\mathrm{X}_{13}$ & $1.195053^{*} 10^{-10}$ \\
$\mathrm{X}_{3}$ & 0.99599683 & $\mathrm{X}_{14}$ & $6.917708^{*} 10^{-10}$ \\
$\mathrm{X}_{4}$ & $8.365369 * 10^{-9}$ & $\mathrm{X}_{15}$ & $4.182685 * 10^{-9}$ \\
$\mathrm{X}_{5}$ & $7.967019 * 10^{-10}$ & $\mathrm{X}_{16}$ & $5.967018^{*} 10^{-10}$ \\
$\mathrm{X}_{6}$ & 0.99599683 & $\mathrm{X}_{17}$ & $7.195053^{*} 10^{-10}$ \\
$\mathrm{X}_{7}$ & $5.975264 * 10^{-10}$ & $\mathrm{X}_{18}$ & $1.195053^{*} 10^{-10}$ \\
$\mathrm{X}_{8}$ & 0.99671455 & $\mathrm{X}_{19}$ & $7.967018^{*} 10^{-10}$ \\
$\mathrm{X}_{9}$ & $7.060781^{*} 10^{-10}$ & $\mathrm{X}_{20}$ & $5.519103^{*} 10^{-10}$ \\
$\mathrm{X}_{10}$ & $1.190553 * 10^{-10}$ & $\mathrm{X}_{21}$ & $6.779018^{*} 10^{-9}$ \\
$\mathrm{X}_{11}$ & 0.99649514 & & \\
\end{tabular}

Analyzing the results shown in Table5, we can draw the following conclusions:

(1) The probability importance of the basic events like $X_{2} 、 X_{3} 、 X_{6} 、 X_{8} 、 X_{11}$ is much higher than others, and the influence of the change of the top event is larger. The result is consistent with the final investigation report released by NTSB(National Transportation Safety Board)in America. 
(2)To avoid the similar flight conflict, we should find the safety loopholes and solve them in time, such as shortening time to reduce the controller's workload, and strengthening the pilots study of basic flight rules.

\section{Conclusions}

In this paper, the HAZOP method is introduced into the field of air traffic control. The way to apply the method to the hazard list, to find the potential security risks and to provide a reliable basis for decision makers are described at length. Problems have been solved that when boundaries of many top events are not clear, there being much overlap and duplication among FTs; that some events being missed because of subjectivity; that the vague of key points if FT is too big or too complex as a result of the ambiguity of top events. The HAZOP can be used for reference in flight conflict analysis of terminal area.

\section{Acknowledgement}

In this paper, the research was sponsored by the Nature Science Foundation of Shaanxi Province (Project No. 2015JM7364).

\section{References}

[1] FU Xiyan.Spread the HAZOP technology and Improve the Technology level of safety[J] .Modern Occupational Safety,2011. (124): 20-33.

[2] CHEN Yong, LAI Xiaolin.Recent research progress of HAZOP analysis method and its application[J].Petrochemical Safety and Environment Protection Technology.2013.29(4) : 30-33.

[3] QIN Baolu, ZHANG Liqun,etc.Analysis of Mid-Air Collision Accidents and Incidents[M], XI’AN:The Blue Sky Press,2015.

[4] Hands.H.de Jong, Sybert H.Stroeve \& Henk A P Blom.The role of air traffic controllers and pilots in safety risk analysis[R].Amsterdam: National Aerospace Laboratory (NLR), 2006.

[5] Steven Shorrock, Barry Kirwan, Ed Smith. Human error prediction in Air Traffic Management: Acomparison of two approaches[R] London: International Broadcast Center(IBC)Conferenceon Preventing Human Errors and Violations, 2003.

[6] FENG Geng, JIANG Yuhong, FAN Lu,etc.Earth Dam Risk Analysis Based on FTA and BN[J] ,Water Power,2013,39(4): 34-36.

[7]LI Shumin,SUN Shudong,SI Shubin.A Modular Method for Multi-State Fault Tree Reliability Analysis [J].Journal of Northwestern Polytechnical University,2014,32(2): 251-253.

[8] XU Weiru.The Introduction to air traffic control[M].Beijing: The Blue Sky Press,2008. 